\title{
Age-Related Changes in Calretinin-Immunoreactive Periglomerular Cells in the Rat Main Olfactory Bulb
}

\author{
In Koo HWANG ${ }^{1)}$, Ki-Yeon $\mathrm{YOO}^{1)}$, Young Sam NAM ${ }^{2)}$, Jung Hoon $\mathrm{CHOI}^{2)}$, Kangmoon $\mathrm{SEO}^{3)}$, In $\mathrm{Se} \mathrm{LEE}^{2)}$, \\ $\mathrm{Ju}$ Young JUNG ${ }^{1)}$, Tae-Cheon $\mathrm{KANG}^{2)}$, Yang-Seok $\mathrm{OH}^{4)}$ and Moo Ho $\mathrm{WON}^{1) *}$
}

${ }^{1)}$ Department of Anatomy, College of Medicine, Hallym University, Chunchon 200-702, 2)Departments of Anatomy, College of Veterinary Medicine and School of Agricultural Biotechnology and ${ }^{3)}$ Department of Veterinary Surgery, College of Veterinary Medicine, Seoul National University, Seoul 151-742 and ${ }^{4}$ Department of Medical Genetics and Experimental Animal Center, College of Medicine, Hallym University, Chunchon 200-702, South Korea

(Received 31 August 2005/Accepted 12 January 2006)

ABSTRACT. The changes of calretinin (CR)-immunoreactive periglomerular cells in the glomerular layer of the main olfactory bulb (MOB) were investigated in rats differing ages from postnatal month 1 (PM 1) to PM 24. The number of cresyl violet-positive periglomerular cells was similar between PM 1 and PM 12, but they decreased slightly in the PM 24 group. The size of CR-immunoreactive periglomerular cells in the glomerular layer increased with age, while their numbers did not change significantly in the PM 6-PM 24 groups. In the PM 24 group, numbers of CR-positive periglomerular cell bodies and their processes decreased, while the size of CR-positive cell bodies in the glomeruli was larger than that of the previous groups. These results suggest that CR-immunoreactive periglomerular cells in the rat MOB are well-developed in the PM 6 group, and that periglomerular cells in the PM 24 group show poor CR-immunoreactivity compared to those in the PM 6 group.

KEY WORDS: aging, calretinin, degeneration, periglomerular cells, SD rat.

J. Vet. Med. Sci. 68(5): 465-469, 2006

The main olfactory bulb in all vertebrates is represented by a rostral extension of the forebrain and superficially receives olfactory nerve fibers from nasal olfactory cells. In the olfactory glomeruli, dendrites from the projecting neurons of the olfactory bulb receive synapses from the axons of the olfactory receptor cells with an important local modulation $[6,19,20]$. In the glomerular layer, cells constitute a simple neuronal population according to morphological criteria by Golgi impregnation: external tufted cells, periglomerular cells and superficial short-axon cells $[15,18]$.

External tufted cells are involved in rapid and topographically organized interbulbar and intrabulbar interactions, while periglomerular cells and superficial short-axon cells are the first and the second interneurons, respectively, and they also modulate olfactory information at the glomerular level. Among these cells, the periglomerular cells are very important role in odor decoding because these cells modulate the glomerular processing $[1,5,13,15]$.

Calretinin (CR), one of the major calcium binding proteins in the olfactory system, is popular in the glomerular layer. CR in the periglomerular cells regulates intracellular calcium levels and could buffer calcium transients resulting from their different cellular processes $[3,7]$. Although substantial numbers of human studies have suggested that functional olfactory deficits increase with age and age-related illnesses, relatively little work has described in the normal aging process of animal models. In the present study, we investigated age-related changes of CR immunoreactivity in the glomerular layer of the rat main olfactory bulb (MOB),

\footnotetext{
* Correspondence to: Prof. Won, M. H., Department of Anatomy, College of Medicine, Hallym University, Chunchon 200-702, South Korea.
}

which is a gatekeeper of olfactory system.

\section{MATERIALS AND METHODS}

Experimental animals: Male Sprague-Dawley rats were purchased from Harlan and were bred at the Experimental Animal Center, Hallym University, Chunchon, South Korea. The animals were supplied kindly by Dr Oh, a chief in the Experimental Animal Center, Hallym University. Postnatal month 1 (PM 1) $(n=7)$, PM $3(n=7)$, PM $6(n=7)$, PM $12(n=7)$, and PM $24(n=7)$ rats were housed in conventional state under adequate temperature $\left(23^{\circ} \mathrm{C}\right)$ /and humidity $(60 \%) /$ control with a $12-\mathrm{hr}$ light/12-hr dark cycle, and provided with free access to water and diet containing crude protein (20\% of diet) (Cheil Jedang, South Korea). Procedures involving animals and their care conformed to the institutional guidelines which are in compliance with current international laws and policies (NIH Guide for the Care and Use of Laboratory Animals, NIH Publication No. 8523, 1985, revised 1996) and were approved by the Hallym's Medical Center Institutional Animal Care and Use Committee. All experiments were conducted to minimize the number of animals used and suffering.

Tissue processing: To obtain the exact data in this study, tissues in various aged groups were processed at the same moment within the same day. For histology, the animals were anesthetized with pentobarbital sodium $(30 \mathrm{mg} / \mathrm{kg})$ and perfused transcardially with $0.1 \mathrm{M}$ phosphate-buffered saline (PBS, $\mathrm{pH} 7.4$ ) followed by $4 \%$ paraformaldehyde in $0.1 \mathrm{M} \mathrm{PB}(\mathrm{pH} 7.4)$. Olfactory bulbs were removed and postfixed with the same solution for $4 \mathrm{hr}$. The tissues were cryoprotected by infiltration with $30 \%$ sucrose overnight. 
Thereafter the frozen tissues were serially sectioned in 30 $\mu \mathrm{m}$ thickness transversely with a cryostat and then collected into six-well plates containing PBS.

Cresyl violet staining: To obtain the number of periglomerular cells in the glomerular layer in various aged groups, the sections were mounted on gelatin coated microscopic slides. Cresyl violet (CV) acetate (Sigma, MO) was dissolved at $1.0 \%(\mathrm{w} / \mathrm{v})$ in distilled water, and glacial acetic acid was added in this solution. Before and after staining for $2 \mathrm{~min}$ at room temperature, the sections were washed twice in distilled water, dehydrated by placing successively for 2 hr in $50 \%, 70 \%, 80 \%, 90 \%, 95 \%, 100 \%$ ethanol bathes at room temperature, and finally mounted with Canada Balsam (Kato, Japan) [8].

Immunohistochemistry for $C R$ : To obtain the exact data for immunohistochemistry, free-floating sections of various aged groups ( $n=7$ at each group) were processed by immunohistochemistry at the same moment within the same day. The immunohistochemical procedures were conducted as previously mentioned protocol $[9,11]$.

The adjacent sections stained with $\mathrm{CV}$ were sequentially treated with $0.3 \%$ hydrogen peroxide $\left(\mathrm{H}_{2} \mathrm{O}_{2}\right)$ in PBS for 30 min and $10 \%$ normal horse serum in $0.05 \mathrm{M}$ PBS for 30 min. They were next incubated with mouse anti-CR antibody (diluted at 1:5,000, Chemicon International, U.S.A.) overnight at room temperature and subsequently exposed to biotinylated horse anti-mouse $\operatorname{IgG}$ (diluted 1:200, Vector, U.S.A.) and streptavidin peroxidase complex (diluted 1:200, Vector, U.S.A.). Then, the sections were visualized with 3,3'-diaminobenzidine in $0.1 \mathrm{M}$ Tris-HCl buffer ( $\mathrm{pH}$ 7.2) and mounted on the gelatin-coated slides.

In order to establish the specificity of the immunostaining, a negative control test was carried out by substituting normal mouse serum for primary antibody or by omitting the primary antibody. The negative control showed the absence of immunoreactivity in any structures.

Quantification of data and statistical analysis: All measurements were performed in order to ensure objectivity in blind conditions, by two observers for each experiment, carrying out the measures of control and experimental sections at the same moment in the same day. The sections were previously selected according to anatomical landmarks corresponding to the plates 1-2 (for the coronal main olfactory bulb) of the Paxinos and Watson [17] rat brain atlas.

For quantitative analysis of $\mathrm{CR}$ immunoreactivity in the main olfactory bulb, 10 sections in each animal were randomly selected within the corresponding levels of the main olfactory bulb. All the CR-immunoreactive areas taken from glomerular layer in the MOB were obtained through an Axiophot light microscope at a magnification of 25-50 $\times$ (Carl Zeiss, Germnay) connected via CCD camera to a PC monitor. Video images were digitized into an array of 512 $\times 512$ pixels corresponding to a tissue area of $140 \times 140 \mu \mathrm{m}$ $(40 \times$ primary magnification). To evaluate the density of CR-immunoreactive areas, the CR-positive fibers or neurons were selected by interactively determining each cell limit using the imageJ software, in which each pixel resolu- tion was of 256 gray levels. The intensity of CR immunoreactivity was evaluated by means of a relative optical density (ROD) value which was obtained after transformation of mean gray values using the formula: $\mathrm{ROD}=\log (256 /$ mean gray). The values of background staining were subtracted from ROD values of all immunoreactive structures before statistical processing. ROD values were informed as ROD units. In addition, the soma size of CR-immunoreactive cells was measured and the morphology of their processes was recorded in the glomerular layer.

Measurement of neuronal number was also performed using an image analyzing system equipped with a computerbased CCD camera (software: Optimas 6.5, CyberMetrics, U.S.A.). Numbers of CR- and CV-positive cells were counted through 10 sections in each animal and 20 glomeruli in each section, and were compared to those in the PM 1 group.

Individual differences in each group, as well as interexperimental differences, were not significant statistically. Differences among the means were statistically analyzed by means of a Student's two-tailed $t$-test. Statistical significance was set to $* \mathrm{P}<0.05$ or $* * \mathrm{P}<0.01$.

\section{RESULTS}

The CV-positive cells within periglomerular cells Changes in cresyl violet positive cells: Cresyl violet (CV) positive periglomerular cells in the glomerular layer changed in the rat MOB with age (Fig. 1). The number of CV-positive periglomerular cells was similar between the PM 1 and the PM 12 group, in which they were about 420 in a glomerulus; however, they significantly decreased in the PM 24 group, showing 380 in a glomerulus.

The CR-immunoreactive cells within periglomerular cells: CR-immunoreactive periglomerular cells were detected in the glomerular layer in all groups. In the PM 1 group, they were scattered in the glomerular layer (Fig. 2A), averaging 62.3 cells in a glomerulus and $14.6 \%$ of periglomerular cells in a glomerulus (Fig. 1). In the PM 3 group, the number of CR-immunoreactive cells was similar to that in the PM 1 group (Figs. 1 and 2B). Their average number was 65.4 (15.6\% of periglomerular cells in a glomerulus).

In the PM 6 group, the number of CR-immunoreactive periglomerular cells significantly increased in the glomerular layer compared to that in the PM 3 group (Figs. 1 and $2 \mathrm{C})$, showing their highest numbers ( $19.8 \%$ of periglomerular cells in a glomerulus). The number of CR-immunoreactive cells in the PM 12 group was similar to that in the PM 6 group (Fig. 1).

In the PM 24 group, the number of CR-immunoreactive periglomerular cells decreased compared to that in the PM 12 group, but was higher than that in the PM 1 group in proportion of CR-immunoreactive cells in a glomerulus (Figs. 1 and 2D). In this group, the average number of CR immunoreactive cells was 71.6 (18.8\% of periglomerular cells in a glomerulus) (Fig. 1).

Changes in CR-immunoreactive structures: The size and 
processes of CR-immunoreactive periglomerular cells in the rat MOB changed with age. In the PM 1 group, most of cells had oval somata, but no processes (Fig. 2A). In the PM 3 group, CR-immunoreactive periglomerular cells possessing

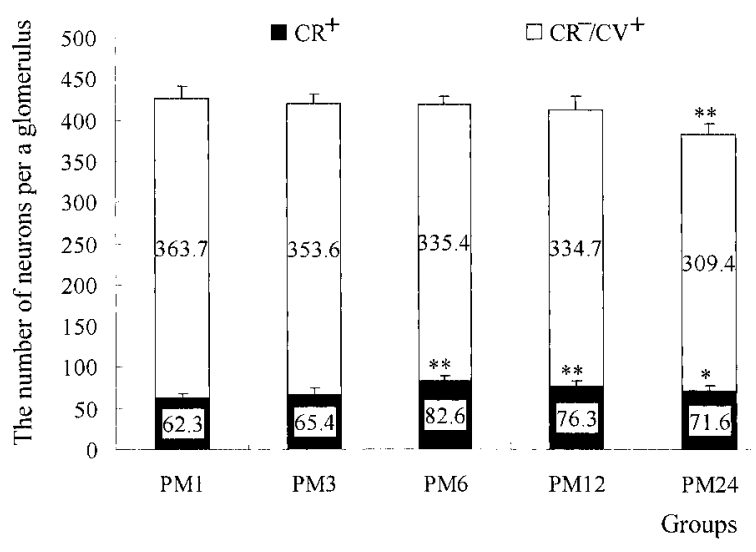

Fig. 1. The average number of $\mathrm{CR}$ immunoreactive $\left(\mathrm{CR}^{+}\right)$periglomerular cells per a glomerulus in the main olfactory bulb at various age stages in rats $(* \mathrm{P}<0.05, * * \mathrm{P}<0.01$, significant differences from PM 1 group). The close part of histogram indicates the number of $\mathrm{CR}^{+}$periglomerular cells and the open part of histogram indicates $\mathrm{CR}$ negative $\left(\mathrm{CR}^{-}\right)$periglomerular cells of cresyl violet positive $\left(\mathrm{CV}^{+}\right)$periglomerular cells. The bars indicate the means \pm S.D.
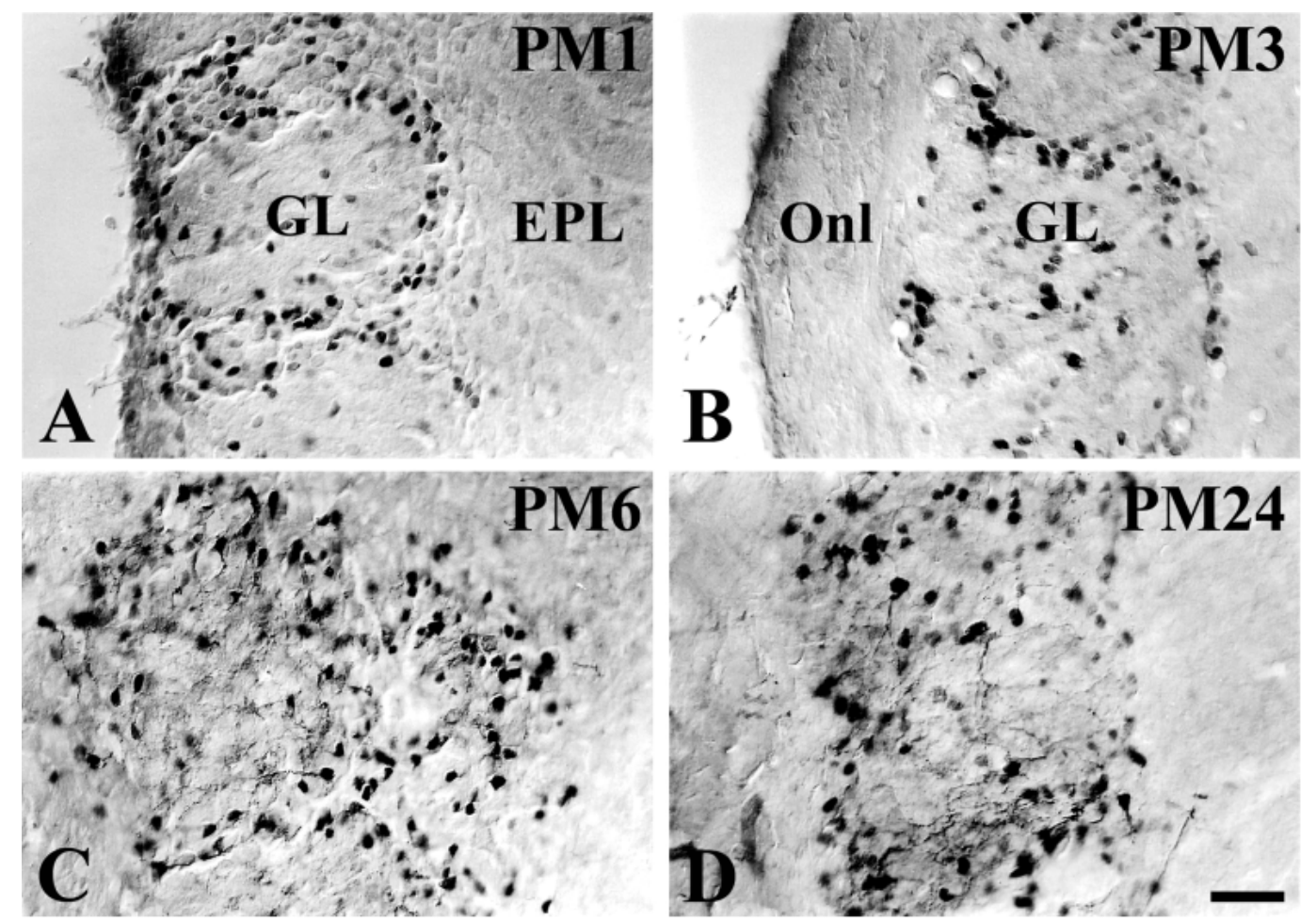

Fig. 2. Immunohistochemical staining for $\mathrm{CR}$ in the glomerular layer of the rat main olfactory bulb at PM 1 (A), PM 3 (B), PM 6 (C) and PM 24 (D). Note that the number and size of CR-positive cells significantly increases at PM 6 (C) and PM 24 (D): at these age stages, CR-positive fibers are predominantly distributed in glomeruli. Bar $=50 \mu \mathrm{m}$. short processes increased slightly in size averaging $(4.95 \pm$ $0.21) \times(7.56 \pm 0.35) \mu \mathrm{m}$ (Fig. 2B); however, the ROD values of total CR-immunoreactive structures in the glomerular layer were similar to those in the PM 1 group (Fig. 3).

In the PM 6 group, the size of CR-immunoreactive somata and their ROD values were detected to increase significantly in the glomerular layer compared to those in the PM 3 group (Figs. 2C and 3), in which the size of CR-immunoreactive somata increased by averaging $(4.99 \pm 0.32) \times$ (7.92 \pm 0.26$) \mu \mathrm{m}$. These CR-positive cells had complicated processes with numerous varicosities and spines, displaying mature feature (Fig. 2C). The morphology of CR-positive cells and their ROD values in the PM 12 group were similar to those in the PM 6 group (Fig. 3). However, the size of CR-immunoreactive cell bodies slightly grew by $(5.79 \pm$ $0.42) \times(8.74 \pm 0.54) \mu \mathrm{m}$ compared to that in the PM 6 group.

In the PM 24 group, the size of CR-immunoreactive cell bodies increased by averaging $(6.09 \pm 0.49) \times(9.84 \pm 0.63)$ $\mu \mathrm{m}$ in the glomerular layer, while their processes were poor compared to that in the PM 12 group (Fig. 2D), although the ROD values were similar to those in the PM 12 group (Fig. 3).

\section{DISCUSSION}

In the previous study, it has been reported that age-related

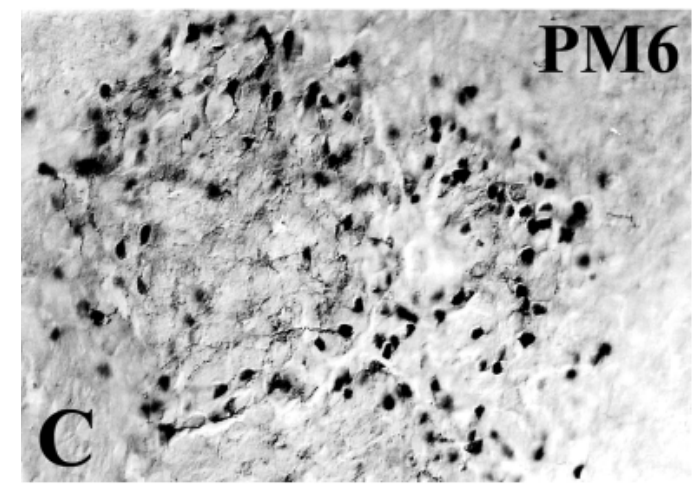




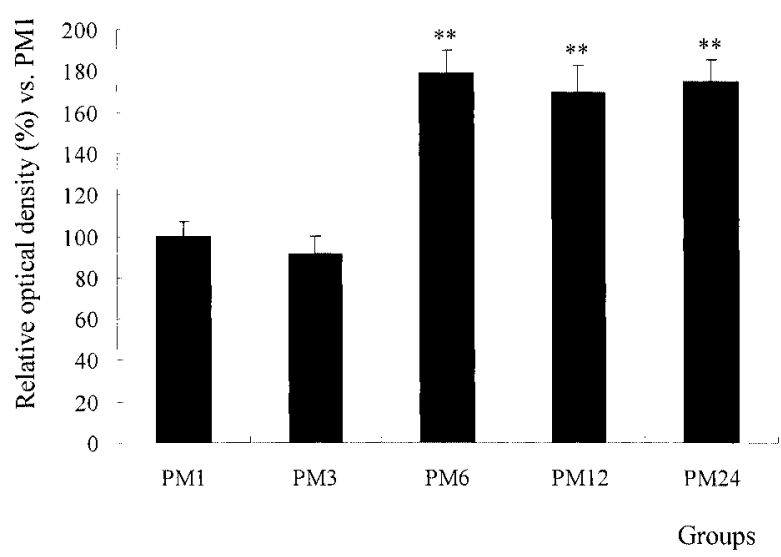

Fig. 3. The ROD of CR-immunoreactive structures in the glomerular layer at various age stages. The results of the quantitative data obtained using image analysis are consistent with the immunohistochemical data $(* * \mathrm{P}<0.01$, significant difference from PM 1 group). The bars indicate the means \pm S.D.

changes of somatostatin-immunoreactive cells were detected in the granule cell layer of the rat MOB [11], in which significant numbers of their neurons were observed in the PM 24 group, although their processes were shorter than those in the PM 12 group. In addition, age-related changes of calbindin D-28k (CB) and parvalbumin (PV) immunoreactivity in the rat $\mathrm{MOB}$ were observed, showing the highest numbers of the former cells in the PM 6 group and the latter neurons in the PM 3-6 group, respectively $[9,10]$. The PVpositive neurons had also satellite somata with well-developed processes containing many varicosities. Finally, there was significant decrease in number of CB- and PV-positive neurons in the MOB in the PM 24 group.

In the present study, we observed the age-related changes of CR-immunoreactive periglomerular cells in the glomerular layer of the rat MOB. The size of CR-positive cells in this region increased with age, while their numbers showed the pattern of reverse $U$ shape with age. In addition, the total number of periglomerular cells decreased in the PM 24 group. In the PM 6 group, CR-positive cells peaked in number, showing nearly $20 \%$ of the total number of periglomerular cells. In addition, it was found that CR-positive cells in the rat MOB were well-developed in the PM 6 group. This finding was very similar to the previous result that $\mathrm{CR}$ immunoreactivity was well-defined at the neurons in the glomerular layer of the adult rat MOB [13].

Mirich et al. [14] reported that CR-positive cells in the mouse olfactory bulb remained stably throughout the life, in which the subset of interneurons stained positively for CR was detected constantly in all strains. In the present study, numbers of CR-positive cells did not change significantly among PM 6-24 groups.

The present study showed that the ROD values of total CR-immunoreactive structures in the periglomerular cells in the PM 24 group did not change significantly compared to those in the PM 6 and 12 groups. This finding was sup- ported by the studies that CR immunoreactivity in the glomerular layer of the adult rat preserves the cell from damage due to a sustained rise in this cation concentration, and/or affects the amplitude of calcium entrance and its timing because CR buffers intracellular calcium or shortens calcium oscillations $[2-4,7]$.

In conclusion, $\mathrm{CR}$ immunoreactivity changes with age in periglomerular cells of the rat MOB: CR-positive periglomerular cells are well-developed in PM 6 rats unlike other calcium binding proteins such as $\mathrm{CB}$ and $\mathrm{PV}$. In addition, $\mathrm{CR}$ in periglomerular cells may play an important role for the modulation of calcium in the main olfactory bulb.

ACKNOWLEDGEMENTS. The authors would like to thank Mr. Seok Han, Mr. Seung Uk Lee and Ms. Hyun Sook Kim for their technical help for this study. This work was supported by grant (R05-2003-000-11175-0) from the Basic Research Program of the Korea Science \& Engineering Foundation. This research was supported by the Research Grant from Hallym University, Korea.

\section{REFERENCES}

1. Alonso, J.R., Arévalo, R., Porteros, A., Briñón, J.G., Lara, J. and Aijión, J. 1993. Calbindin D-28K and NADPH-diaphorase activity are localized in different populations of periglomerular cells in the rat olfactory bulb. J. Chem. Neuroanat. 6: 1-6.

2. Andressen, C., Blümcke, I. and Celio, M.R. 1993. Calciumbinding proteins: selective markers of nerve cells. Cell Tissue. Res. 271: 181-208.

3. Baimbridge, K.G., Celio, M.R. and Rogers, J.H. 1992. Calcium-binding proteins in the nervous system. Trends Neurosci. 15: 303-308.

4. Briñón, J.G., Alonso, J.R., Garcia-Ojeda, E., Crespo, C., Arévalo, R. and Aijión, J. 1997. Calretinin- and parvalbuminimmunoreactive neurons in the rat main olfactory bulb do not express NADPH-diaphorase activity. J. Chem. Neuroanat. 13: 253-264.

5. Crespo, C., Aloso, J.R., Briñón, J.G., Weruaga, E., Porteros, A., Arévalo, R. and Aijón, J. Calcium-binding proteins in the periglomerular region of typical and atypical olfactory glomeruli. Brain Res. 745: 293-302.

6. Haláz, N. 1990. The vertebrate olfactory system. Chemical Neuroanatomy, Function and Development. Akadémiai Kiadó, Budapest.

7. Heizmann, C.W. and Hunziker, W. 1991. Intracellular calcium-binding proteins: more sites than insights. Trends Biochem. Sci. 16: 98-103.

8. Hwang, I.K., Eum, W.S., Yoo, K.Y., Cho, J.H., Kim, D.W., Choi, S.H., Kang, T.C., Kwon, O.S., Kang, J.H., Choi, S.Y. and Won, M.H. 2005. Copper chaperone for Cu,Zn-SOD supplement potentiates the $\mathrm{Cu}, \mathrm{Zn}-\mathrm{SOD}$ function of neuroprotective effects against ischemic neuronal damage in the gerbil hippocampus. Free Radic. Biol. Med. 39: 392-402.

9. Hwang, I.K., Kang, T.C., Lee, J.C., Lee, I.S., Park, S.K., An, S.J., Jeong, Y.G., Seo, J.G., Oh, Y.S. and Won, M.H. 2002. Age-related change of calbindin D-28k immunoreactive neurons in the rat main olfactory bulb. Neurosci. Lett. 326: 159162.

10. Hwang, I.K., Kim, D.S., Lee, H.Y., Lee, J.Y., Choi, G.P., Lee, D.I., Kim, J.D., Lee, Y.B., Sohn, H.S., Kang, T.C. and Won, 
M.H. 2003. Age-related changes of parvalbumin immunoreactive neurons in the rat main olfactory bulb. Mol. Cells 16: 302306.

11. Hwang, I.K., Lee, J.C., Park, S.K., An, S.J., Lee, H.Y., Lee, Y.B., Sohn, H.S., Lee, I.S., Kang, T.C. and Won, M.H. 2004. Age-related change of somatostatin-immunoreactive neurones in the main olfactory bulb of the rat. Anat. Histol. Embryol. 33: 59-63.

12. Kishimoto, J., Tsuchiya, T., Cox, H., Emson, P.C. and Nakayama, Y. 1998. Age-related changes of calbindin-D28k, calretinin, and parvalbumin mRNAs in the hamster brain. Neurobiol. Aging 19: 77-82.

13. Kosaka, K., Aika, Y., Toida, K., Heizmann, C.W., Hunziker, W., Jacobowitz, D.M., Nagatsu, I., Streit, P., Visser, T.J. and Kosaka, T. 1995. Chemically defined neuron groups and their subpopulations in the glomerular layer of the rat main olfactory bulb. Neurosci. Res. 23: 73-88.

14. Mirich, J.M., Williams, N.C., Berlau, D. and Brunjes, P.C. Comparative study of aging in the mouse olfactory bulb. $J$. Comp. Neurol. 454: 361-372.

15. Nakajima, T., Okamura, M., Ogawa, K. and Taniguchi, K. 1996. Immunohistochemical and enzyme histochemical characteristics of short axon cells in the olfactory bulb of the golden hamster. J. Vet. Med. Sci. 58: 903-908.
16. Papazafiri, P., Podini, P., Meldolesi, J. and Yamaguchi, T. 1995. Ageing affects cytosolic $\mathrm{Ca}^{2+}$ binding proteins and synaptic markers in the retina but cytosolic $\mathrm{Ca}^{2+}$ binding proteins and synaptic markers in the retina but not in cerebral cortex neurons of the rat. Neurosci. Lett. 186: 65-68.

17. Paxinos, G. and Watson, C. 1998. The Rat Brain in Stereotaxic Coordinates, 4th ed., Academic Press, San Diego.

18. Pinching, A.J. and Powell, T.P.S. 1972. The neuron types of the glomerular layer of the olfactory bulb. J. Cell. Sci. 9: 305345.

19. Shimada, A., Irie, M., Kojima, S., Kobayashi, K., Yamano, Y. and Umemura, T. 1996. Immunohistochemical localization of metallothionein in the olfactory pathway of dogs. J. Vet. Med. Sci. 58: 983-988.

20. Soeta, S., Izu, Y., Saito, T.R., Yamano, S. and Taniguchi, K. 2005. Differential expression of neurofilament 200-like immunoreactivity in the main olfactory and vomeronasal systems of the Japanese Newt, Cynops pyrrhogaster. J. Vet. Med. Sci. 67: 701-706.

21. Villa, A., Podini, P., Panzeri, M.C., Racchetti, G. and eldolesi, J. 1994. Cytosolic $\mathrm{Ca}^{2+}$ binding proteins during rat brain ageing: Loss of calbindin and calretinin in the hippocampus, with no change in the cerebellum. Eur. J. Neurosci. 6: 1491-1499. 